\title{
Informação e valor: inter-relações conceituais e a formação das tipologias valorativas da informação'
}

\author{
Information and value: Conceptual interrelations \\ and the formation of evaluative types of information
}

Jonathas Luiz Carvalho SILVA²

\section{Resumo}

Este artigo trata das inter-relações entre informação e valor, apontando uma intrínseca relação entre ambos os termos. Apresenta como ponto de partida a seguinte pergunta: quais as inter-relações entre informação e valor e como elas produzem impactos na produção das tipologias valorativas da informação? O trabalho tem como objetivo abordar fundamentos sustentadores do conceito de valor, percebendo como este se inter-relaciona com o conceito de informação, considerando a formação das tipologias valorativas da informação no contexto causal e consequencial. A metodologia é concebida a partir de uma pesquisa bibliográfica, em diálogo com literatura documental diversa sobre os conceitos de valor e de informação, tanto da Ciência da Informação quanto de áreas afins, como Filosofia, Sociologia, Ciência Política, História, Educação, Linguística, Psicologia, Comunicação, entre outras. Conclui que a grande inter-relação entre informação e valor é constituída por meio das questões causais e consequenciais, sendo estas questões observadas sob uma perspectiva de construção social baseada em interações que estimulam a tomada de decisão dos sujeitos.

Palavras-chave: Informação. Valor. Valores causais da informação. Valores consequenciais da informação.

\begin{abstract}
The article deals with the interrelationships between information and value with an intrinsic relation between the two terms. The starting point of the article is the following question: What are the interrelationships between information and value and how do these interrelations produce an impact on the production of types of evaluative information? The objective is to address the underlying fundamentals of the concept of value by perceiving how these concepts interrelate to the concept of information and considering the formation of the types of evaluative information in the causal and consequential context. The methodology was based on a bibliographical research in dialogue with different documentary literature on the concepts of value and information, both in Information Science and related areas such as Philosophy, Sociology, Political Science, History, Education, Linguistics, Psychology, Communication, among others. It may be concluded a perspective of social construction based on interactions that stimulate the decision making of the subjects. that the interrelationship between information and value is developed by causal and consequential issues; these issues observed from a coordinated point of view are one of the main phenomen a that promote the dynamics and construction of information among the subjects (rever texto original).
\end{abstract}

Keywords: Information. Value. Causal values of information. Consequential values of information.

\footnotetext{
1 Artigo elaborado a partir da tese de J.L.C. SILVA, intitulada "Múltiplas interlocuções da informação no campo da Ciência da Informação no âmbito dos fundamentos técnico-pragmáticos, humanos e científicos". Universidade Federal da Bahia, 2014.

2 Universidade Federal do Cariri, Centro de Ciências Sociais Aplicadas, Programa de Pós-Graduação em Biblioteconomia. Av. Tenente Raimundo Rocha, s/n., Bairro Cidade Universitária, 63048-080, Juazeiro do Norte, CE, Brasil. E-mail: <jonathascarvalhos@yahoo.com.br>. 


\section{Introdução}

A percepção de valor é eminentemente relacionada à apropriação da realidade objetiva, referente à apropriação de conceitos e baseada nas crenças dos sujeitos. A percepção de valor é atividade central na construção da informação, de modo que a informação sem a definição dos valores que a norteiam é uma informação estanque e sem dinâmica históricoprática. Essa afirmação é ponto-chave para discussão e compreensão deste artigo.

O conceito de valor vem acompanhando a história da humanidade desde sua mais tenra idade. Esse transcurso trouxe inúmeras interpretações e transformações ao conceito de valor, conforme as interpretações científicas e as percepções de determinadas sociedades em determinados tempos históricos.

O tema da referente pesquisa é relevante no sentido de situar as percepções conceituais de informação atreladas aos significados de valor, considerando que a semântica informacional carrega consigo um conjunto de potencialidades causais e consequenciais de valor.

O tema de pesquisa é desenvolvido contemplando as seguintes razões:

(a) acadêmico-científica - concernente ao estímulo de novas vertentes de pesquisas e aplicações teórico-metodológicas sobre o conceito de informação, vinculadas ao conceito de valor;

(b) filosófica - atinente à construção de novas percepções conceituais de informação, compreendida não como um conceito isolado, mas como conceito associativo a diversos outros conceitos/terminologias como valor.

Desse modo, o presente tema de pesquisa toma como base a concepção de que os conceitos de valor contribuem de forma múltipla e direta para a construção conceitual e teórico-prática de informação, sendo pertinente abordar no desenvolvimento do artigo como eles concorrem para a construção causal e consequencial da informação e como auxiliam na formação das tipologias valorativas da informação.

O artigo apresenta como ponto de partida a seguinte pergunta: quais as inter-relações entre in- formação e valor e como elas produzem impactos na produção das tipologias valorativas da informação? O trabalho tem como objetivo abordar fundamentos sustentadores do conceito de valor, percebendo como esses conceitos se inter-relacionam ao conceito de informação, considerando a formação das tipologias valorativas da informação no contexto causal e consequencial.

\section{Procedimentos metodológicos}

A metodologia do artigo é sustentada por uma pesquisa bibliográfica que busca, mediante o diálogo com bibliografias diversas como livros e artigos sobre as temáticas 'valor' e'informação', conceber uma interlocução teórico-conceitual que dimensione as múltiplas relações entre ambas as terminologias.

No que se refere ao conceito de valor, é fundamental o diálogo com bibliografias de Nietzsche (2001) e Rokeach (1973), imprimindo um viés filosófico e aplicativo do conceito e tipologias de valor. Já no que tange ao conceito de informação, o ponto de partida estratégico-bibliográfico está situado em Bateson (1973) e Mackay (1969), agregando também um locus filosófico e aplicativo do conceito de informação. Os quatro autores são fundantes para construção da pesquisa bibliográfica e, associados com outros estudiosos, como Capurro (2010), Deleuze (2008), Floridi (2008, 2009), Marx (1988) e Simmel (1983), possibilitam revelar as relações entre os conceitos de informação e de valor no âmbito das perspectivas causais e consequenciais, assim como a formação das tipologias valorativas da informação.

O artigo versa sobre as inter-relações entre informação e valor como conceitos baseados na noção de diferença e, ainda, sobre a formação de tipologias valorativas da informação, sejam causais (valor humano, social, econômico, histórico-cultural, político, educativo, religioso, científico e ético), sejam consequenciais (valor de produtividade, serviço, organização, uso, troca, compra, venda e sociativo), buscando explicar o significado de cada valor mencionado e suas possíveis proximidades. 


\section{Percepções preliminares sobre o conceito de valor}

O conceito de valor tem se desenvolvido em diversas áreas do conhecimento. Na Economia (e extensivamente em alguns campos das ditas Ciências Sociais Aplicadas), a noção de valor é dividida em uso e troca, sendo que "[...] o primeiro diz respeito às características físicas dos bens que os capacitam a ser usados pelo homem, ou seja, satisfaz necessidades de qualquer ordem, materiais ou ideais; o segundo indica a proposição em que os bens são intercambiados uns pelos outros, direta ou indiretamente, por intermédio do dinheiro" (SANDRONI, 2000, p.625).

$\mathrm{Na}$ "semiótica"' e na "linguística" ou, mais precisamente, na "semiolinguística"' o conceito de valor é dividido em três paradigmas: linguístico, conhecido como campo das equivalências (SAUSSURE, 1975); antropológico, correspondente ao contexto das trocas (BERTRAND, 1987; GREIMAS, 1981, 1983; LANDOWSKI, 1991); e tímico-tensivo, relativo às tensões (GREIMAS, 1983, 2002; GREIMAS; COURTÉS, 1986).

O conceito de valor também é estudado no Direito, instanciado pela Teoria Pura do Direito, principalmente no que se refere à reflexão jurídicofilosófica proposta por Hans Kelsen, que estuda a noção de valor relacionada ao conceito de justiça e à separação entre moral e direito (KELSEN, 1998), e por Norberto Bobbio, que investiga o valor relacionado à concepção de ética (BOBBIO, 1992).

No campo das Ciências Humanas, há forte carga de estudos conceituais sobre valor, concebidos e propagados transversalmente em áreas como a Filosofia, Sociologia, Ciência Política, História, Educação, Linguística, Psicologia, Comunicação e Ciência da Informação, entre outras, em particular por meio das reflexões desenvolvidas por Marx, que vê o valor vinculado ao trabalho, como fundamento social, e ainda à luta de classes.

Na Ciência da Informação, os estudos sobre valor ainda são muito vagos, mas, de forma geral, são aplicados em centros de informação vinculados a empresas, indústrias, bancos e instituições de pesquisa (KIELGAST; HUBBARD, 1997) ligados à gestão da informação e mais precisamente focalizados em tomadas de decisão em ambientes organizacionais
(MORESI, 2000), ou ainda no setor ligado aos serviços de informação, relacionados à gestão e/ou tecnologias da informação.

Diante do breve relato, é preciso fazer jus à importância da Filosofia para estudar e propor conceitos de valor. Nietzsche (2001) faz uma síntese do conceito histórico de valor, afirmando que a característica do maior período da história da humanidade, a pré-história, foi valorar uma ação segundo suas consequências; o ato importava tão pouco quanto suas origens. Entretanto, em meados do Século XIX a situação mudou, e o valor deixou de ser atribuído às consequências da ação para se focalizar sobre suas causas. Isso representa um acontecimento importante, produto de um grande refinamento do juízo - o efeito distante e inconsciente dos valores aristocráticos e da crença nas 'origens', o sinal distintivo de um período que se poderia denominar de período moral da humanidade, definitivamente o primeiro passo para o conhecimento de si mesmo. Por isso, a ação ocorre ao inverso e em lugar de se procurarem as consequências, trata-se de encontrar a origem, sendo essa inversão fruto de longas lutas e prolongadas atribuições e uma singular estreiteza de interpretação, que chegou para dominar atravessando o caminho. A origem de um ato, no sentido mais estrito do termo, está ligada a uma intenção, em que esta é por si só a origem e a pré-história da ação.

Em uma clara crítica ao conceito de valor desde as chamadas comunidades primitivas até as sociedades do período moderno, Nietzsche imprime a ideia de que o valor fincado nas consequências incide sobre uma percepção deformada de moral, pois não desencadeia os processos valorativos da moral humana. Assim sendo, quais as grandes diferenças entre o conceito de valor vinculado às consequências e o conceito de valor vinculado às causas/origens?

A primeira grande diferença é que o valor ligado às causas/origens valoriza as reflexões sobre o fenômeno ontológico individual e social desde o limiar de uma questão até seu 'desfecho', estabelecendo preocupação direta com o processo e os diversos contextos envolvidos. De outro lado, o valor ligado às consequências não se preocupa com o processo ontológico, mas apenas com o produto concretizado das causas, visualizando uma situação reducionista sobre a realidade ontológica. 
A segunda grande diferença reside no fato de que o valor das causas envolve a compreensão dos procedimentos das forças impostas pelos sujeitos para chegar a determinados resultados, enquanto o valor das consequências envolve apenas os resultados em si. Ou seja, o valor das causas é processual, permitindo a lógica compreensiva dos resultados, ao passo que o valor das consequências leva em conta apenas os resultados em si, sem uma contextualização processual.

Em suma, o valor das causas está eminentemente preocupado com o 'ser', enquanto o valor calcado nas consequências está pautado no 'ter'. O valor é, portanto, um fenômeno de atribuição multitemporal e um processo baseado nos pensamentos, discursos e ações dos sujeitos, principalmente nas forças de interação e dominação que exercem entre si. Rokeach (1973, p.25) pondera que:

Dizer que uma pessoa tem um valor é dizer que ela tem uma crença prescritiva ou provável que um específico modo de comportamento ou estado-final da existência é preferido a um modo oposto de comportamento ou estadofinal. Essa crença transcende a atitude em relação a objetos ou em direção a situações; ela é um padrão que guia e determina ação, atitudes em relação a objetos ou situações, ideologia, apresentação de si mesmo aos outros, avaliações, julgamentos, justificações, comparações de si mesmo com os outros e tentativa de influenciar os outros.

O valor significa a reunião - coordenada ou descoordenada, multitemporal ou temporal, pluricontextualista ou unicontextualista - de elementos da história de vida dos sujeitos relativas às ideologias, culturas, comportamentos, questões hereditárias, desenvolvimentos cognitivos e linguísticos que constituem um arsenal de crenças que norteiam a conduta psíquica (moral e intelectual) dos sujeitos. Destarte, tem-se uma mutualidade designada entre valor e realidade objetiva (história de vida e cotidiano social e hereditário) dos sujeitos. O valor só pode ser constituído a partir da realidade objetiva dos sujeitos, no sentido de que são crenças elaboradas no seio da vida e da pragmática humana. Esse mesmo valor, após apreendido e apropriado da realidade objetiva, é organizado e registrado na mente dos sujeitos, com vistas à futura utilização para nova modificação da realidade objetiva.
Essa mutualidade é expressa na linha de raciocínio: Realidade objetiva $\rightarrow$ Apropriação de valor $\rightarrow$ Novas práticas para transformação da realidade objetiva. Essa linha não é necessariamente rígida, pois nem todos os valores permitem a transformação da realidade objetiva. Esta pode também ser mantida, na seguinte linha de raciocínio: Realidade objetiva $\rightarrow$ Apropriação de valor $\rightarrow$ Manutenção da realidade objetiva.

A diferença entre ambas as linhas de raciocínio é que a primeira pode determinar contextos de partiIha ou dominação entre sujeitos, enquanto a segunda necessariamente está focalizada nos processos de dominação, pois reside no ideário de conformação e permanência de um estado de vida. O termo "apropriação de valor" é aqui utilizado em face da percepção de valor ser adaptada à realidade de vida (crenças, comportamentos, culturas e ideologias) do sujeito. A apropriação do conceito (nesse caso de valor) é concebida, conforme Vygotsky (1995), como primeiramente social e posteriormente individual, já que é a partir da realidade objetiva que a percepção de valor se estabelece como fenômeno de apropriação e conotação teórica de sentidos.

Para compreender a pragmaticidade dos valores, Rokeach (1973) elenca dois tipos basilares: (a) valores terminais - vida próspera, vida excitante, mundo de paz, igualdade, liberdade, felicidade, segurança, prazer, salvação, reconhecimento social, amizade verdadeira, sabedoria, mundo belo (natureza e artes), segurança familiar, amor maduro, respeito próprio, senso de realização, harmonia interna; (b) valores instrumentais - ambicioso, mente aberta, capaz, alegre, limpo, corajoso, generoso, prestativo, honesto, imaginativo, independente, intelectual, lógico, amoroso, obediente, polido, responsável, autocontrolado.

Os valores instrumentais podem ser vistos como aqueles destinados aos procedimentos para alcançar determinadas finalidades. Já os valores terminais são aqueles finalísticos e passíveis de concretização. Adaptando essa tipologia ao pensamento de Nietzsche (2001) sobre os valores de causa/origem e valores de consequência, é possível afirmar que os valores terminais são considerados de consequência, pois são valores concretizados sem que necessariamente 
se saiba quais foram os meios empregados para tal concretização, enquanto os valores instrumentais denotam de forma mais clara as causas pelas quais determinados sujeitos empreendem certas ações.

O fato é que ambos os tipos de valores, em Nietzsche (2001) e Rokeach (1973), devem ser analisados em permanente concatenação, pois a plena compreensão de um deles não é possível sem a inclusão do outro. O uso para análise de apenas um tipo de valor promove apropriações deturpadas, incompletas e provavelmente tendenciosas da realidade objetiva.

\section{Inter-relações entre informação e valor: das tipo- logias causais e consequenciais}

No que tange às possíveis inter-relações entre informação e valor, podem-se destacar duas questões fundamentais que as norteiam: a informação como construto da diferença e as tipologias valorativas da informação. Quanto à primeira questão, parte-se dos conceitos de Mackay (1969), quando diz que a informação é uma distinção que faz a diferença, e de Bateson (1973, p.428), que considera ser a informação a "diferença que faz a diferença". Esses dois conceitos, que parecem ser complementares (possivelmente o segundo tomou como base o primeiro), denotam uma percepção muito clara de que a inter-relação entre informação e valor é fortemente influenciada pelo conceito de diferença.

O conceito de diferença tem vários indícios implícitos e explícitos, como: informação como fenômeno de negação e afirmação (DELEUZE, 2008); diferença como fenômeno de identificação daquilo que o outro é (SILVA, 2000); diferença como fenômeno de pertencimento dos sujeitos a determinados objetos; diferença como fundamento de identificação e particularização configuracional dos sujeitos. Diante dos conceitos de diferença apresentados, é preciso um olhar cauto sobre os conceitos de informação de Bateson (1973) e Mackay (1969).

Em primeira instância, o conceito de Mackay (1969) pode parecer redundante quando utiliza os termos distinção e diferença. No entanto, o termo distinção não é usado diretamente como diferença (embora esteja ligado à concepção de diferença), mas como destaque ou ênfase e como sentido ou significado. Assim, a informação é a ênfase de sentido (ou significado) que faz a diferença.

Em outras palavras, para Mackay (1969), a informação é a ênfase de sentido que: (a) estabelece prelúdios para identificação dos sujeitos a um determinado contexto de pertencimento, (b) permite delimitar algumas características de valor informacional dos sujeitos e (c) contribui para negação ou afirmação de valor dos sujeitos em relação a outros. Nos dois primeiros casos (identificação e características de valor informacional dos sujeitos), o conceito de informação de Mackay (1969) está essencialmente relacionado à percepção de identidade, já que "a afirmação da identidade e a marcação da diferença implicam, sempre, as operações de incluir e de excluir. Como vimos, dizer 'o que somos' significa também dizer o que não somos" (SILVA, 2000, p.82). Assim, o conceito de informação apresenta particularidades de valores informacionais produzidos pelos sujeitos, caracterizando suas identidades. No terceiro caso, o conceito de informação é complementar aos dois primeiros, pois o que impera é a diferença de valor entre os sujeitos. O conceito de informação preconiza, não uma configuração identitária em si, mas aquilo que torna um sujeito diferente do outro por meio dos valores informacionais produzidos. O valor da informação produzido pelos sujeitos possui a capacidade múltipla (e também intencionalidades múltiplas) de externalizar, marginalizar, afirmar ou negar valores.

Normalmente, o conceito de informação como diferença tem a pretensão de superestimar os valores de um sujeito em detrimento dos valores do outro, rejeitando-os; ou, ainda, de simplesmente externalizar valores, o que denotaria indiferença quanto aos valores informacionais produzidos por outros sujeitos (os sujeitos produzem informações, mas estão preocupados mais em expressar os seus próprios valores informacionais do que em receber os de outros). Em síntese, o conceito de informação elaborado por Mackay (1969) é um fenômeno que marca os sujeitos, tornando-os particulares em suas construções de valor, bem como destaca esses sujeitos conforme suas consistências e conveniências de ênfase de sentido. Por isso, a informação, quando produzida, diferencia os sujeitos - exaltando, rejeitando ou tratando com indiferença -, pois sintomaticamente 
estimula a produção de valores, sejam eles humanos, profissionais, pessoais, espirituais, etc.

O conceito de Bateson (1973), por sua vez, é mais categórico quando utiliza diferença duas vezes. Mas é preciso ponderar que os termos 'diferença' utilizados possuem conotações diferentes. A primeira ocorrência do termo 'diferença' é alusiva aos significados de produção da informação concebidos pelo sujeito e armazenados em suas mentes. Já a segunda ocorrência é concernente aos efeitos causados pela informação após aplicada pelo sujeito em algum contexto. Assim, a "diferença" primeiramente utilizada por Bateson (1973) possui significado abstrativo e de apropriação lógico-ontológica da realidade objetiva, enquanto a segunda possui finalidade eminentemente pragmática, a partir das ações dos sujeitos da informação.

O conceito de informação em Bateson (1973) presume que a informação possui dois momentos distintos mas complementares: o primeiro incide sobre como os sujeitos conseguem lidar com a realidade objetiva, incluindo outros sujeitos, e produzir informações que modifiquem suas estruturas cognitivas e sociais; o segundo reside na capacidade do sujeito de utilizar o conceito de informação apropriado conforme sua conveniência. Dessa maneira, a diferença que faz a diferença, mais uma vez, coloca a informação como processo de forças humanas (heurísticas positivas e negativas dos sujeitos para se apropriar da informação e aplicá-la em determinado contexto, conforme os valores gestados) e não-humanas (os instrumentos que os sujeitos utilizam para se apropriar da informação e aplicá-la conforme seus valores) que interferem nas condições psíquicas e no modus operandi dos sujeitos.

É preciso afirmar que os conceitos de Bateson (1973) e MacKay (1969) são contextualistas, pois levam em consideração que "o significado da informação é dado pelo processo que a interpreta" (FREDKIN, 2005). Eis que é nesse aspecto que informação e valor são inseparáveis: se a informação é vista como processo que leva em consideração o contexto, são precisamente os valores dos sujeitos (ideológicos, culturais, políticos, religiosos, familiares, etc.) que estimulam determinadas produções informacionais, as quais, por sua vez, ajudam a concretizar e/ou modificar os valores pregados pelos sujeitos.
Isso significa que a relação entre informação e valor é uma constituição intrínseca expressa pela seguinte lógica: Valor (baseado na história de vida dos sujeitos) $\rightarrow$ Produção da informação (processo de interpretação e apropriação da realidade objetiva) $\rightarrow$ Contextos em que os sujeitos pretendem utilizar a informação $\rightarrow$ Concretização e/ou modificação de valores (novos sentidos valorativos produzidos pelos sujeitos).

Diante de tais considerações, afirma-se aqui que o conceito de informação baseado na diferença é relacionado aos contextos em que os sujeitos estão situados e aos valores que produzem em suas trajetórias. Por isso, o presente estudo discorda enfaticamente da máxima "agregue valor além da informação", já que toda e qualquer informação possui uma carga de valor, e que todo valor interfere diretamente nas práticas informacionais. Nesse sentido, considera-se aqui que a informação possui dois grandes tipos de valor: valores causais e valores consequenciais. O primeiro é considerado como fundamento teórico-prático e refere-se ao caráter moral e humano da informação, envolvendo o valor humano, social, econômico, cultural, político, religioso e ético. O segundo é considerado de aspecto mais pragmático e pontual, e refere-se ao caráter processual da informação, envolvendo as formas de organização, uso, venda compra, troca, compartilhamento e sociação. Esses valores são delimitados no Quadro 1 e merecem, por sua vez, análise mais cuidadosa.

Quadro 1. Valores da Informação.

\begin{tabular}{ll}
\hline Valores Causais & Valores Consequenciais \\
\hline Valor humano & Valor de produtividade \\
Valor social & Valor de serviço \\
Valor econômico & Valor de organização \\
Valor histórico-cultural & Valor de uso \\
Valor político & Valor de troca \\
Valor educativo & Valor de compra \\
Valor religioso & Valor de venda \\
Valor científico & Valor de compartilhamento \\
Valor ético & Valor sociativo \\
\hline
\end{tabular}

Fonte: Silva (2014).

Quanto aos valores causais da informação, apontam-se as seguintes observações: 
a) valor humano: esses são os valores cruciais da informação, na medida em que indicam formas de comportamento dos sujeitos da informação em suas ações cotidianas. Os valores humanos permeiam como os sujeitos da informação agem em torno de práticas como educação (formal e informal), consciência ambiental (formas de comportamento no tocante ao uso dos recursos naturais e energéticos), exclusão/ inclusão social, relação familiar, honestidade, amor ao próximo, ética e cidadania. São considerados valores fundamentais, porque são eles que determinam as intencionalidades de ação dos sujeitos quando da produção informacional;

b) valor social: esse é um valor permanentemente coletivo, pois só pode ser concretizado nas relações e forças (impositivas ou socializadoras) dos sujeitos da informação. O valor social da informação implica em como um sujeito pretende produzir informação com relação a outro, e como vê o outro como sujeito (potencial ou concreto) de produção informacional. O valor social da informação é coletivo, na medida em que a informação produzida por um sujeito tem sua base herdada das estratégias de apropriação da realidade objetiva. O valor social da informação também pode significar as combinações culturais, educacionais e políticas para melhorar a vida das pessoas em termos de ação e construção de sentido;

c) valor econômico: designa a informação como produto, mercadoria ou bem de consumo a ser comercializada, vendida, trocada, comprada ou passível de negociação comercial. O valor econômico preconiza que a informação é vista como um produto, serviço ou até mesmo um recurso: único, de natureza específica e características muito próprias, podendo substituir outros recursos, como dinheiro, matéria-prima, etc. (FERNANDES, 1991). O valor econômico da informação é um dos mais recorrentes, pois demonstra factivelmente as condições dos sujeitos em obter informação e a viabilização em massa de como os produtos e serviços de informação orientam as práticas cotidianas. Por exemplo, quais sujeitos podem dispor de determinadas tecnologias e documentos/artefatos para produzir informação; ou quais sujeitos institucionais possuem mais condições econômicas de lidar com outros sujeitos institucionais, visando produzir informação. 0 valor econômico da informação comumente mostra o caráter excludente da sociedade, na medida em que a informação tem um sentido de competitividade, possessividade e materialidade (consumo de produtos informacionais). Esse valor é o motor das relações entre os sujeitos em todo o mundo, já que determina quem é passível de ter acesso aos produtos informacionais e pode utilizá-los da forma mais conveniente, além de promover sistemas de informação para acesso e consumo da informação. Em síntese, a informação é vista aqui como mercadoria, tanto por meio de suas substâncias materiais (tecnologias e documentos/artefatos), quanto por meio de suas substâncias comerciais;

d) valor histórico-cultural: ocorre quando a informação auxilia na formação das crenças, valores e costumes de um sujeito ou comunidades. A informação é relevante como valor histórico-cultural porque serve como uma espécie de guia para conduta dos sujeitos durante suas trajetórias, contribuindo tanto para construção individual quanto para construção coletiva. Isso quer dizer que o valor da informação está intrinsecamente concatenado a sua atualidade e possibilidade de aplicação no contexto cultural, visto que "o processo de envelhecimento da informação é associado à perda gradativa de seu valor com a passagem do tempo: quanto mais velha a informação menos valor terá" (OBERHOFER, 1991, p.121). Considera-se que a atualidade da informação é crucial para compor o repertório de valores culturais dos sujeitos, pois favorece formas de vida coletiva, por meio do compartilhamento de crenças e costumes promovidos pelo repertório informacional dos sujeitos. No entanto, no contexto histórico, a ideia de atualidade da informação amplia-se quando se quer abranger um conjunto mais ampliado de gerações, pois a atualidade da informação depende, sobretudo, do tempo histórico-cultural que está sendo abarcado para uma efetiva contextualização social. Com efeito, "a informação não existe fora do tempo, fora do processo: ela aumenta, diminui, transporta-se e conserva-se no tempo" (ZEMAN, 1970, p.162);

e) valor político: está associado à capacidade dos sujeitos, em nível individual ou coletivo, público ou privado, de analisar situações da realidade e tomar decisões, visando benefícios a determinados grupos. A informação é um catalisador que reconhece 
problemas, possibilita reflexões e encaminha soluções, garantindo caráter processual de diálogo público, registro do pensamento, construção de ideias e práticas executivas. O valor político da informação é relacionado ao "conjunto de lutas que atores sociais e políticos empreendem para impor uma leitura do problema que seja a mais vantajosa aos seus interesses" (DEUBEl, 2007, p.58);

f) valor educativo: reflete sobre como os sujeitos aprendem e produzem conhecimentos a partir das informações que são apropriadas. O valor educativo da informação possui caráter pragmático (age no cotidiano dos sujeitos) e institucional (agregado a instituições como família, escola, universidade, igreja, etc.), e se configura como

[...] um mecanismo de intervenção sobre o real, que atua por meio de formas de organização estruturada, utilizando-se de recursos materiais, tecnológicos, simbólicos e relacionais, que atingem os comportamentos e condutas afetivas, cognitivas e comunicativas dos indivíduos (PIERUCCINI, 2004, p.42).

g) valor religioso: preconiza os sentidos que os sujeitos produzem para fundamentação espiritual, incluindo a fé e o amor a um ser superior. Esse tipo de valor é diferente de todos os outros pelos seguintes traços: a informação é um subsídio determinado por documentos/artefatos que atuam como espécie de guia do que deve ser produzido como informação; o valor da informação é baseado em um fundamentalismo que tem a finalidade de persuadir outros sujeitos do que é verdadeiro em termos espirituais; o valor da

$\underline{\mathbf{2 7 4}}$ informação é proselitista e prima pela linearidade discursiva da aceitação dos sujeitos. O valor religioso da informação, embora espiritual, está diretamente ligado aos aspectos do cotidiano social, no sentido de que os sujeitos que praticam esse valor informacional estão interessados em compartilhar suas informações;

h) valor científico: designa a possibilidade da informação como valor de produção de novos conhecimentos que sirvam para embasar a opinião de comunidades acadêmico-científicas e profissionais. O valor científico da informação também se insere na capacidade dos sujeitos em problematizar, refletir e resolver problemas dos mais diversos tipos. O valor científico da informação também é pertinente para: incentivar o acesso seletivo à informação; favorecer o acesso à informação para as comunidades consideradas mais carentes; estimular o caráter comercial e industrial da informação como sendo favorável a um grupo minoritário de sujeitos; fomentar o acesso aberto à informação como novo paradigma da comunicação científica (SWAN, 2008); dinamizar as políticas de informação no sentido de organizar, armazenar e promover acesso à informação por diversos espaços físicos e virtuais (ORTELLADO, 2008). Pode-se afirmar que os valores científicos da informação são paradoxais na medida em que pregam situações conflitantes de acordo com as ideologias dos produtores (e das comunidades discursivas) desse tipo de informação;

i) valor ético: concernente ao comportamento informacional dos sujeitos condizentes com a conduta moral. O valor ético da informação inclui os processos normativos de produção, acesso e apropriação da informação e se interpõe a partir de desafios interculturais éticos de cunho teórico (discussões em torno de uma fundamentação do discurso ético que oscila entre posturas universalistas e relativistas) e prático (busca de um código global para a sociedade da informação) (CAPURRO, 2010). O valor ético também está condicionado aos construtos da ética global da comunicação, de caráter pragmático e baseada nas interações entre diversas culturas e gerações. Esta coloca como ponto de partida as seguintes interpelações: quais os princípios éticos que tomam como base o diálogo em que se fundamenta a ética global da informação? existe uma macroética pautada no consequencialismo, no deontologismo ou no contratualismo? (FLORIDI, 2009). Vale ressaltar que a ética global da informação deve ser pensada a partir da ética ontocêntrica, na qual, segundo Floridi (2008, p.12), "o 'receptor' da ação, o paciente, é situado no cerne do discurso ético [...], enquanto que o 'transmissor' de qualquer ação moral, o agente, é movido para sua periferia" implicando dizer que a ética ontocêntrica é voltada para realidade do ser/ente.

Os valores causais da informação designam aquilo que é necessário para viver em termos de sentidos idealísticos. São valores condutivos que indicam o que deve ou não ser feito. Envolve os sentidos dos 
princípios e finalidade da ação humana. No caso dos valores causais, a informação, seja temporária ou permanente, agrega valor na trajetória dos sujeitos. A informação como valor causal é abstrativa, quando o sujeito precisa de compreensão interlocutora de vida; é teórica, quando o sujeito define parâmetros reflexivos de conduta; e é ainda política, quando o sujeito precisa decidir o que fazer a partir das informações produzidas - esse ato político é permanentemente renovado em torno de uma ética ontocêntrica da informação.

Já os valores consequenciais da informação são designados a partir das seguintes funções:

a) valor de produtividade: toda informação, em qualquer contexto ou suporte, é produzida com vistas à satisfação de necessidades, desejos ou demandas. O conceito de produtividade informacional é estritamente institucional e está situado na capacidade dos sujeitos, em caráter individual e principalmente coletivo, de aliar qualidade de trabalho com qualidade de produção. A produtividade consiste em "minimizar cientificamente o uso de recursos materiais, mão de obra, equipamentos etc., para reduzir custos de produção, expandir mercados, aumentar o número de pessoas empregadas, lutar por aumentos reais de salários e pela melhoria do padrão de vida no interesse comum do capital, trabalho e consumidores" (MORIKAWA, 2010, p.1030). De forma mais objetiva, o valor produtivo da informação diz respeito à capacidade dos sujeitos institucionais que atuam em centros de informação, em espaços organizacionais (comerciais, empresariais, industriais e bancários) ou em espaços virtuais de informação, desenvolvendo atividade gerencial de qualidade e oferecendo serviços que visem à satisfação das necessidades de informação dos usuários/clientes;

b) valor de serviço: é consequência do valor de produtividade. O valor de serviço implica a capacidade de oferecer um produto ou processo ao usuário/ cliente com vistas a satisfazê-lo. O valor informacional do serviço reside em atividades como: atendimento, processo de solicitação de pedidos, rapidez na resposta dos pedidos, padrões de consultas dos serviços, divulgação do serviço em diversos espaços, qualidade do produto ou processo oferecido. O valor de serviço afere que "a informação é todo o esclarecimento que se possa dar a qualquer pessoa sobre o que ela indaga [...]" (FERNANDES, 1991, p.165);

c) valor de organização: é relativa ao valor estruturador da informação no sentido de disponibilizá-la da forma mais adequada possível para os sujeitos da informação. Esse valor significa que "a informação que está ligada à organização está ligada também à conservação e à transmissão desta organização" (ZEMAN, 1970, p.159);

d) valor de uso: do ponto de vista moral (mais agregado à Biblioteconomia e Ciência da Informação, o termo "uso" é muito amplo e não pode ser pensado de forma isolada. Em verdade, o valor de uso da informação engloba perspectivas de busca, recuperação e apropriação da informação, atreladas ao desenvolvimento de competências, planejamento e manejo com as fontes e tecnologias de informação que sejam salutares para a construção do conhecimento. O uso da informação "compõe-se de atividades em que o indivíduo se engaja para apreender a informação e transformá-la em conhecimento. Compreendem habilidades intelectuais como decodificação, interpretação, controle e organização do conhecimento" (VARELA; BARBOSA, 2012, p.157). Além disso, "a informação é multiplicável - quanto mais for utilizada, mais útil se torna; o limite básico é a idade biológica das pessoas e grupos" (FERNANDES, 1991, p.165). Do ponto de vista econômico, o valor de uso da informação está diretamente relacionado à força de trabalho dos sujeitos em produzir informação por meio de seus esforços físicos, cognitivos e psíquicos. A informação é visualizada como mercadoria desenvolvida para consumo e enriquecimento de quem produz. "Os valores de uso constituem o conteúdo (material da riqueza, qualquer que seja a forma social desta" (MARX, 1988, p.46). O valor de uso da informação, do ponto de vista econômico, é inerente ao uso de equipamentos como tecnologias impressas e/ou digitais, documentos e dispositivos diversos que permitem aos sujeitos produzir informação. O uso está focalizado no contato do sujeito com a materialidade informacional empreendida como mercadoria apropriada para consumo;

e) valor de troca: do ponto de vista moral, o valor de troca da informação é impreciso e praticamente 
impossível de ser mensurado, pois o intercâmbio informacional se dá em um nível abstrativo e a justeza da troca pode ser superficialmente observada a partir da aplicação envidada pelo sujeito da informação em algum contexto concreto que permita alguma conquista (profissional ou pessoal, por exemplo). Isso significa que o valor de troca da informação se dá a partir do compartilhamento de alguma informação pelo sujeito, visando receber nova informação de outro sujeito que Ihe permita conceber novas práticas informacionais. Do ponto de vista econômico, o valor de troca da informação, embora não possa ser mensurado quantitativamente, engloba a expressão de um valor de benefício social mútuo em que os sujeitos envolvidos ganham alguma coisa - uns podem ganhar mais que os outros, dependendo da necessidade ou adequação da troca informacional. O valor de troca "só pode ser o modo de expressão, a 'forma de manifestação' de um conteúdo dele distinguível" (MARX, 1988, p.46). Mais uma vez, o valor de troca da informação no contexto econômico se estabelece na materialidade da informação, significando a troca de suportes informacionais, comumente com características diferentes (trocas de livros ou equipamentos digitais, por exemplo), para promoção de novas formas de uso e apropriação da informação;

f) valor de compra e valor de venda: inicialmente, o valor de compra e venda da informação é estritamente comercial (informação como mercadoria), visto que o objetivo é a obtenção de determinado produto e, para tal intento, é preciso dispor de tempo e recursos financeiros. No entanto, é possível observar o ponto de vista moral quando a preocupação dos sujeitos em vender ou comprar é: 'o que ganharemos ao obter tal informação?' O valor de compra e venda envolve a prática de vantagens competitivas, em um mercado que exige atualizações no consumo de suportes da informação;

g) valor de compartilhamento: talvez seja o valor mais sorrateiro e ambíguo da informação, expressando formas diversas de apropriação, em particular quando concebido por centros e organizações de informação. O valor de compartilhamento da informação caracteriza-se por: partilha e troca entre sujeitos, o que ajuda na construção do conhecimento organizacional e pessoal
(WU, 2008); estímulos para geração de novos conhecimentos (HOOFF; HUYSMAN, 2009); compartilhamento dependente do contexto intencionado pelo sujeito ou pelas organizações. Considera-se aqui que o valor de compartilhamento da informação envolve: intencionalidade (procedimentos para conquistar determinado objetivo); liderança (forma de conquistar espaço de liderança em um grupo); discurso (envidado com vistas a convencer um sujeito ou grupo de que dada informação é correta, embora possa se constituir como informação deformada ou contrainformação); compartilhamento institucional (tentativa forçada ou dialogada de exercer o papel informativo de uma organização sobre uma comunidade ou sociedade); compartilhamento continuado (pautado em informações do cotidiano dos sujeitos, concebidas de forma permanente); compartilhamento transversal (quando grupos diversos - empresas, bancos, indústrias, universidades/escolas, grupos de pesquisadores, sindicatos, movimentos sociais, partidos políticos, ONGs etc. - compartilham informações entre si, visando ao desenvolvimento mútuo);

h) valor sociativo: referente ao conteúdo, à forma e aos processos de interação que definem como as informações são compartilhadas, possibilitando a criação de novas formas sociais. Toda informação compartilhada possui intencionalidades, objetivos e perspectivas, mesmo que não estejam plenamente gestados na consciência dos sujeitos. O valor sociativo da informação é representado por Simmel (1983) em duas passagens esclarecedoras. A primeira manifesta o valor semântico da sociação, considerada como "tudo que está presente nos indivíduos (que são os dados concretos e imediatos de qualquer realidade histórica) sob a forma de impulso, interesse, propósito, inclinação, estado psíquico, movimento - tudo que está presente nele de maneira a engendrar ou medir influências sobre os outros [...] designo como conteúdo, como matéria, por assim dizer, sociação" (SIMMEL, 1983, p.165). A segunda identifica o valor sociativo aplicado à sociedade, quando diz que "aqui, 'sociedade' propriamente dita é o estar com um outro, para um outro, contra um outro que, através do veículo dos impulsos ou dos propósitos, forma e desenvolve os conteúdos e os interesses 
materiais ou individuais" (SIMMEL, 1983, p.168). Assim, o valor sociativo da informação tem dois momentos complementares: o primeiro é inerente à apropriação dos sujeitos a partir da realidade concreta, permitindo a produção de informação; o segundo dá-se quando essa informação apropriada e eivada de sentidos se torna premente de ser aplicada à realidade social, como espécie de retorno daquilo que foi apropriado pelo sujeito. O valor sociativo da informação sintetiza todos os outros valores consequenciais, na medida em que não só indica como os sujeitos podem viver e conviver socialmente, mas também define como são delineados os seus objetivos e finalidades.

Os valores consequenciais valorizam o pragmatismo informacional como ação executada a partir dos valores causais. Evidentemente, esses valores nem sempre são sincronizados, mas estão harmoniosa ou conflituosamente ligados como formas de pensar e agir, teorizar e praticar, guardar e distribuir, calar e falar.

\section{Conclusão}

A informação é eivada de valores. Porém, esses componentes valorativos da informação devem ser expostos e descobertos a partir das práticas de interação entre os sujeitos. Quando se agrega informação, está-se postulando agregar também valores para a construção de sentidos.

Para referenciar a inter-relação entre informação e valor, é fundamental compreender as concepções causais e consequenciais que compõem os valores da informação. Focalizar apenas as consequências pode reduzir a prática informacional, sem dar vazão às causas e procedimentos da construção da informação. Focalizar apenas as causas, por outro lado, pode gerar um eterno problema não resolvido.

Por isso, é primordial, para compreender a inter-relação entre informação e valor, compreender as relações entre causas, procedimentos e consequências. Na questão causal residem os fatores mais amplos e complexos que definem as tipologias valorativas da informação, que agem como espécie de diretrizes dos sujeitos da informação, enquanto na questão consequencial residem os fatores mais pragmáticos e cotidia- nos da realidade dos sujeitos da informação. A questão consequencial pode funcionar como complemento, oposição, divergência ou convergência com a questão causal e, seja qual for essa inter-relação, ela possibilita compreender as origens, o desenvolvimento e a concretização de sentidos da construção da informação pelos sujeitos envolvidos.

As tipologias valorativas da informação mostram quão dinâmica e necessária é a informação na contemporaneidade, pois ela é pertinente para compreender tanto questões imediatas/mediatas, como questões de origem e finalidades das práticas informacionais dos sujeitos.

Desse modo, o presente artigo, ao delinear os valores causais e consequenciais da informação, bem como as tipologias valorativas da informação, aponta não somente fortes traços conceituais e aplicativos em comum entre ambos os conceitos, mas principalmente que é pertinente a continuidade da pesquisa no sentido de compreender os sentidos e o posicionamento de cada valor causal e consequencial da informação e de cada tipo valorativo da informação indicado.

As inter-relações entre informação e valor definem que a informação é, sobretudo, um conceito de construção social que permeia os diversos campos das práticas de cunho causal e consequencial. É pertinente, para estudos posteriores, fundamentar de maneira mais minuciosa a dinâmica das relações (diferenças, semeIhanças, complementos, paradoxos, contradições, etc.) que norteiam os múltiplos significados de informação e valor no âmbito da causalidade e consequencialidade. Em outras palavras, cada valor causal e consequencial da informação concebido neste artigo merece uma explanação mais profunda em futuras pesquisas sobre como dimensionar as inter-relações entre informação e valor, preconizando os vieses acadêmico-científicos e filosóficos delimitados na introdução (justificativa) do artigo.

Portanto, a informação se dá precisamente na condição de movimento dos sentidos, conteúdos, formas, forças e interações de caráter diacrônico ou sincrônico que estimulam os sujeitos a tomar decisões e agir conforme suas acepções valorativas de cunho causal e consequencial. 


\section{Referências}

BATESON, G. Steps to an ecology of mind. St Albans: Paladin Frogmore, 1973.

BERTRAND, D. La justesse. Semiotic Inquiry, v. 13, n. 1-2, p. 37$51,1987$.

BOBBIO, N. A era dos direitos. 11. ed. Rio de Janeiro: Campus, 1992.

CAPURRO, R. Desafíos teóricos y prácticos de la ética intercultural de la información. FREIRE, G.H.A. (Org.). Ética da informação: conceitos, abordagens e aplicações. João Pessoa: Ideia, 2010. p. 11-51.

DELEUZE, G. Diferença e repetição. 2. ed. Rio de Janeiro: Graal, 2008.

DEUBEl, A-N. R. Políticas públicas: formulación, implementación y evaluación. Bogotá: Aurora, 2007.

FERNANDES, P. O. Economia da informação. Ciência da Informação, v. 20, n. 2, p.165-168, 1991.

FLORIDI, L. Information ethics: Its nature and Scope. In: VAN DEN HOVEN, J. Y.; WECKER, J. (Ed.). Information technology and moral philosophy. Cambridge: Cambridge University Press, 2008. p. 40-65.

FLORIDI, L. Information ethics and elobalization. In: GLOBAL FORUM CIVILIZATION AND PEACE. 2009, Republic of Korea. Proceedings... Republic of Korea: The Academy of Korean Studies and Korean National, 2009.

FREDKIN, E. Introduction to digital philosophy. Digital Philosophy, 2005. Available from: <http://www.digitalphiloso phy.org> Cited: May 8, 2014.

GREIMAS, A. J. Semiótica e ciências sociais. São Paulo: Cultrix, 1981.

GREIMAS, A. J. Du Sens Il: éssais sémiotiques. Paris: Seiul, 1983.

GREIMAS, A. J. COURTÉS, J. Sémiotique: dictionnaire raisonné de la théorie du langage. Paris: Hachette, 1986.

GREIMAS, A. J. Da imperfeição. São Paulo: Hacker, 2002.

HOOFF, B.; HUYSMAN, M. Managing knowledge sharing: Emergent and engineering approaches. Information \& Management, v. 46, p. 1-8, 2009.

KELSEN, H. Teoria pura do direito. 6. ed. São Paulo: Martins Fontes, 1998

KIELGAST, S.; HUBBARD, B. A. Valor agregado à informação: da teoria à prática. Ciência da Informação, v. 26, n. 3, p. 271-276, 1997.

LANDOWSKI, E. Dois ensaios de sóciossemiótica. São Paulo: FFLCH, 1991.

MacKAY, D. M. Information, mechanism and meaning. Cambridge: Mit Press, 1969.

MARX, K. O Capital: crítica da economia política. São Paulo:
Nova Cultural, 1988.

MORESI, E. A. D. Delineando o valor do sistema de informação de uma organização. Ciência da Informação, v. 29, n. 1, p. 1424, 2000.

MORIKAWA, M. Labor unions and productivity: an empirical analysis using Japanese firm-level data. Labour Economics, v. 17, n. 6, p. 1030-1037, 2010.

NIETZSCHE, F. W. Para além do bem e do mal ou prelúdio de uma filosofia do futuro. Curitiba: Hemus, 2001.

OBERHOFER, C. M. A. Valor da informação: percepção versus quantificação. Ciência da Informação, v. 20, n. 2, p. 119-129, 1991.

ORTELLADO, P. As políticas nacionais de acesso à informação científica. Liinc em Revista, v. 4, n. 2, p. 186-195, 2008.

PIERUCCINI, I. A ordem informacional dialógica: estudo sobre a busca de informação em educação. 2004. Tese (Doutorado em Comunicação) - Universidade de São Paulo, São Paulo, 2004.

ROKEACH, M. The nature of human values. New York: Free Press, 1973.

SANDRONI, P. (Org.). Novíssimo dicionário de economia. São Paulo: Best Seller, 2000.

SAUSSURE, F. Curso de linguística geral. São Paulo: Cultrix, 1975.

SILVA, J. L. C. Múltiplas interlocuções da informação no campo da Ciência da Informação no âmbito dos fundamentos técnicopragmáticos, humanos e científicos. 2014.490f. Tese (Doutorado em Ciência da Informação) - Universidade Federal da Bahia, Salvador, 2014.

SILVA, T. T. A produção social da identidade e da diferença. In: SILVA, T. T. (Org.). Identidade e diferença: a perspectiva dos estudos culturais. Petrópolis: Vozes, 2000. p. 73-102.

SIMMEI, G. A natureza sociológica do conflito. In: E. MORAIS (Org.). Simmel: sociologia. São Paulo: Editora Ática, 1983.

SWAN, A. Acesso livre: um novo paradigma para a comunicação científica. Liinc em Revista, v. 4, n. 2, p.158-171, 2008.

VARELA, A.; BARBOSA, M. L. A. Trajetórias cognitivas subjacentes ao processo de busca e uso da informação: fundamentos e transversalidades. Encontros Bibli, v. 17, n. 1, p. 142-168, 2012.

VYGOTSKY, L. S. Pensamento e linguagem. São Paulo: Martins Fontes, 1995.

WU, W. Dimensions of social capital and firm competitiveness improvement: The mediating role of information sharing. Journal of Management Studies, v. 45, n. 1, p. 122-146, 2008.

ZEMAN, J. Significado filosófico da noção de informação. In: ZEMAN, J. O conceito de informação na ciência contemporânea. Rio de Janeiro: Paz \& Terra, 1970. p.154-179. 